\title{
Deep Brain Stimulation for the Treatment of Dejerine-Roussy Syndrome
}

\author{
Max Ward Antonios Mammis \\ Department of Neurological Surgery, Rutgers New Jersey Medical School, Newark, NJ, USA
}

\section{Keywords}

Deep brain stimulation - Neuropathic pain .

Dejerine-Roussy syndrome · Poststroke pain · Stroke

\section{Abstract}

Background/Aims: Patients who suffer from Dejerine-Roussy syndrome commonly experience severe poststroke hemibody pain which has historically been attributed to thalamic lesions. Despite pharmacological treatment, a significant proportion of the population is resistant to traditional therapy. Deep brain stimulation is often appropriate for the treatment of resistant populations. In this review we aim to summarize the targets that are used to treat Dejerine-Roussy syndrome and provide insight into their clinical efficacy. Methods: In reviewing the literature, we defined stimulation success as achievement of a minimum of $50 \%$ pain relief. $R \boldsymbol{e}-$ sults: Contemporary targets for deep brain stimulation are the ventral posterior medial/ventral posterior lateral thalamic nuclei, periaqueductal/periventricular gray matter, the ventral striatum/anterior limb of the internal capsule, left centromedian thalamic nuclei, the nucleus ventrocaudalis parvocellularis internis, and the posterior limb of the internal capsule. Conclusions: Due to technological advancements in deep brain stimulation, its therapeutic effects must be reevaluated. Despite a lack of controlled evidence, deep brain stimulation has been effectively used as a therapeutic in clin-

\section{KARGER}

(C) 2017 S. Karger AG, Basel

E-Mail karger@karger.com

www.karger.com/sfn ical pain management. Further clinical investigation is needed to definitively evaluate the therapeutic efficacy of deep brain stimulation in treating the drug-resistant patient population.

(c) 2017 S. Karger AG, Basel

\section{Background}

Dejerine-Roussy syndrome (DRS), also known as thalamic syndrome, thalamic pain syndrome, chronic central pain, and central poststroke pain, is characterized by patients suffering from chronic central neuropathic pain [1-3]. DRS patients have suffered a previous stroke and present often, although not exclusively, with thalamic lesions leading to completely debilitating neuropathic pain $[1,2,4,5]$. The syndrome is thought to be a manifestation of spinothalamic dysfunction, and it has been shown that the relative volume of the spinothalamic pathway in DRS patients is significantly lower than that of controls [6]. Though traditionally characterized as requiring dyesthesia, allodynia, and hyperalgesia [1, 2, 4, 5, 7], DRS can also

An abstract for this work was presented in poster format at the International Neuromodulation Society Conference on May 29-31 in Edinburgh, Scotland.

Max Ward

Department of Neurological Surgery, Rutgers New Jersey Medical School

90 Bergen Street Room 8100

Newark, NJ 07101 (USA)

E-Mail Mw731@njms.rutgers.edu 
occur in stroke patients with normal sensory processing [8]. While patients can develop DRS with normal sensation, the presence of early evoked pain or dyesthesia in conjunction with reduced cold or pinprick sensations significantly increases the odds of developing DRS [9]. The syndrome was first described over 100 years ago by Dejerine and Roussy; however the mechanisms involved are still poorly understood and treatment remains difficult at best $[1,10]$. An estimated $8-12 \%$ of stroke victims will suffer from DRS-related pain within the first year of recovery [11].

In 2012 Hansen et al. [12] proposed that patients suffering from DRS could be identified based on the following criteria $[3,5]$ :

1. Development of pain with onset at or after the stroke

2. Pain located on the stroke-affected side of the body

3. No other plausible cause of the pain, including pain isolated to the shoulder joint and nearby region.

Additionally, patients suffering from DRS often present with deficient temperature and sharpness discrimination, as well as an unexplained burning sensation following the stroke $[5,12-14]$. Pain is often contralateral to the lesion and exacerbated by stimuli such as movement and emotional stress, ranging in severity from mild to incredibly severe pain [5]. This increase in pain has been shown to have significant impacts on the physical functioning of patients, although data on quality of life outcomes is still limited [15].

Although the exact mechanism of DRS is unknown, current theory states that lesions interfering with thalamocortical processing cause increased sensitization to normally nonpainful stimuli $[1,5]$. This "disinhibition theory" is characterized by imbalances, such as an abnormal transmission of thermal or touch stimuli, leading to inappropriate responses such as touch sensitivity or burning pain $[16,17]$. Additionally, thalamic hyperactivity on the contralesional hemisphere and ipsilateral anterior cingulate cortex (ACC) hypoactivity have been observed in patients experiencing allodynia [18]. In a single-patient PET study, cold allodynia of the affected hand was associated with a greater activation of the contralateral somatosensory cortex compared to the control hand [16].

Patients with DRS no longer experience heightened anxiety from the anticipation of pain at the affected location compared to the unaffected side, possibly indicating neuronal habituation to painful stimuli [19]. In this instance, the patient already experiences unrelenting pain, and thus the threat of further stimuli loses salience [19]. Larger neuronal losses after an infarct, in combination with proliferation of glia or microglia in the perilesional

DBS for the Treatment of DRS area, can lead to more severe allodynia [20]. More recent work has shifted the view on DRS into the context of a network remodeling disorder, suggesting that chronic pain states involve mechanisms different from those of typical spontaneous pain $[17,18,21]$. Supporting this viewpoint, complete infarction of the somatosensory cortex can lead to compensatory contralateral hemispheric reorganization $[17,22]$. A recent study showed that the inhibitory mechanism of the thalamocortical GABA system was reversed in a rodent model of the disorder, leading to enhanced spontaneous activity and noxious responses of the thalamus secondary to the development of DRS $[1,20]$.

There is little data on the long-term safety of DBS, particularly in the younger population, despite this issue having been highlighted over 30 years ago [23]. While there is evidence that DBS is a well-tolerated procedure, the more subtle developmental and psychosocial effects of the procedure on developing patients are incompletely understood; however, this issue is unlikely to present in the older poststroke patient population.

Effective treatments for DRS remain elusive. The syndrome is resistant to traditional analgesics, and the efficacy of other pharmacologic agents such as antidepressants and anticonvulsants, many of which target pathophysiologic mechanisms that are present in neuropathic pain, are relatively unstudied $[1,2,5,10,24,25]$. Current pharmacological treatment options are summarized in Table 1 [2, 26-33].

Deep brain stimulation (DBS) has been used to treat chronic pain syndromes since the 1970s; however, early failures severely limited further investigation into the benefits of DBS for the treatment of chronic pain states $[34,35]$. Clinical trials are particularly difficult to perform since the prevalence of DRS is relatively low compared to that of other chronic pain syndromes [36]. As a result, there is little financial incentive for the medical industry to invest in such costly trials [36]. Despite these barriers, DBS has been shown to be an effective last resort in patients who are refractory to other treatments $[2,5,35,37$, 38]. In this manuscript, we discuss the landscape of DBS targeting as a tool for the treatment of DRS, and recent work which drives the field forward.

\section{Methods}

A PubMed search was conducted using the following key words: "Central Pain Syndrome' AND DBS”, "'Central Pain Syndrome' AND 'Deep Brain Stimulation”, "'Dejerine-Roussy syndrome’ AND DBS”, “Dejerine-Roussy syndrome’ AND 'Deep

Stereotact Funct Neurosurg 2017;95:298-306 DOI: $10.1159 / 000479526$ 
Table 1. Current pharmacological treatment options

\begin{tabular}{|c|c|c|c|}
\hline Drug & Mechanism of action & Dosage & Effectiveness \\
\hline Pregabalin & $\begin{array}{l}\text { Voltage-gated calcium channel } \\
\text { antagonist }\end{array}$ & $\begin{array}{l}75 \mathrm{mg} \text { twice daily for } 2 \text { weeks, } \\
150 \mathrm{mg} \text { twice daily for } 2 \text { weeks, and } \\
300 \mathrm{mg} \text { twice daily for } 8 \text { weeks }\end{array}$ & $\begin{array}{l}\text { Effectiveness equal to that of } \\
\text { lamotrigine, with a better side effect } \\
\text { profile }\end{array}$ \\
\hline Amitriptyline & $\begin{array}{l}\text { Balanced monoamine reuptake } \\
\text { inhibition }\end{array}$ & $75 \mathrm{mg}$ daily for 4 weeks & $\begin{array}{l}\text { Effective, safe, and well tolerated, } \\
\text { with mild side effects (pain } \\
\text { reduction was significantly different } \\
\text { from that achieved with a placebo) }\end{array}$ \\
\hline Phenytoin & $\begin{array}{l}\text { Voltage-gated sodium channel } \\
\text { blockade }\end{array}$ & $\begin{array}{l}\text { Serum level between } 10.4 \text { and } \\
22.6 \mathrm{ug} / \mathrm{mL}\end{array}$ & Inconclusive \\
\hline Carbamazepine & $\begin{array}{l}\text { Voltage-gated sodium channel } \\
\text { blockade }\end{array}$ & $800 \mathrm{mg}$ daily for 4 weeks & Minimally effective \\
\hline Lamotrigine & $\begin{array}{l}\text { Presynaptic voltage-gated sodium } \\
\text { channel inhibition reducing the } \\
\text { release of presynaptic transmitters }\end{array}$ & $\begin{array}{l}\text { Started at } 50 \mathrm{mg} \text { daily and elevated } \\
\text { to } 200 \mathrm{mg} \text { daily }\end{array}$ & Moderately effective and tolerated \\
\hline Topiramate & $\begin{array}{l}\text { Voltage-gated sodium channel } \\
\text { blockade and inhibition of glutamate } \\
\text { release by an action on AMPA/kinase } \\
\text { receptors }\end{array}$ & $\begin{array}{l}25 \mathrm{mg} \text { twice daily, increased by } \\
50 \mathrm{mg} \text { weekly up to } 200 \mathrm{mg} 3 \text { times } \\
\text { daily }\end{array}$ & Inconclusive \\
\hline Gabapentin & $\begin{array}{l}\text { Binding to a } 2 \delta \text { subunit of presynaptic } \\
\text { voltage-dependent calcium channels } \\
\text { with a reduced release of presynaptic } \\
\text { transmitters }\end{array}$ & $\begin{array}{l}\text { Started at } 300 \mathrm{mg} 3 \text { times daily } \\
\text { for } 3 \text { days, gradually raised to } \\
1,800-2,400 \mathrm{mg} \text { daily for } 8 \text { weeks }\end{array}$ & Tolerated but not effective \\
\hline Zonisamide & $\begin{array}{l}\text { Voltage-gated sodium channel } \\
\text { blockade }\end{array}$ & $200 \mathrm{mg}$ daily & Inconclusive \\
\hline Lidocaine & $\begin{array}{l}\text { Blockade of sodium channels thus } \\
\text { preventing ectopic discharges }\end{array}$ & $\begin{array}{l}5 \mathrm{mg} / \mathrm{kg} \text { i.v. over } 30 \mathrm{~min} \text { every } \\
2-6 \mathrm{~h}\end{array}$ & Effective for a short period of time. \\
\hline Mexiletine & $\begin{array}{l}\text { Blockade of sodium channels thus } \\
\text { preventing ectopic discharges }\end{array}$ & $\begin{array}{l}200 \mathrm{mg} \text { daily increased to } \\
400-800 \mathrm{mg} \text { daily }\end{array}$ & $\begin{array}{l}\text { Moderate pain relief in } 3 \text { out of } 12 \\
\text { patients }\end{array}$ \\
\hline Ketamine & NMDA receptor antagonist & $5 \mathrm{mg}$ every $5 \mathrm{~min}$ for $25 \mathrm{~min}$ & $\begin{array}{l}\text { Only appropriate in patients who } \\
\text { are refractory to other treatments } \\
\text { ( } 40 \% \text { pain reduction in } 11 \text { out of } 23 \\
\text { patients, } 2 \text { experienced worsening of } \\
\text { the pain) }\end{array}$ \\
\hline Tramadol & $\begin{array}{l}\text { Opioid receptor agonist and } \\
\text { monoamine reuptake inhibitor }\end{array}$ & $\begin{array}{l}50 \mathrm{mg} \text { i.v. over } 5 \mathrm{~min} \text {, followed by } \\
20 \mathrm{mg} \text { oral codeine phosphate and } \\
25 \mathrm{mg} \text { oral milnacepram twice daily }\end{array}$ & $\begin{array}{l}\text { Inconclusive (shown to be beneficial } \\
\text { in } 1 \text { patient) }\end{array}$ \\
\hline Morphine & $\begin{array}{l}\text { Opioid receptor agonist and } \\
\text { monoamine reuptake inhibitor }\end{array}$ & $\begin{array}{l}2 \mathrm{mg} \text { i.v. every } 10 \text { min until side } \\
\text { effects (nausea, vomiting, } \\
\text { somnolence, etc.) begin to present }\end{array}$ & Ineffective, with frequent side effects \\
\hline
\end{tabular}

Brain Stimulation"”, “Thalamic Pain Syndrome' AND DBS”, “Thalamic Pain Syndrome' AND 'Deep Brain Stimulation"”, “Thalamic Syndrome' AND 'Deep Brain Stimulation”, “Thalamic Syndrome' AND DBS", "Dejerine-Roussy Syndrome", "Central Post Stroke Pain", and "Thalamic Pain Syndrome". The search returned 187 total matches. Articles for this review were obtained from these matches or the articles referenced within them.

Although investigators may indicate success as any pain reduction providing clinical benefit to the patient, in evaluating the clinical effectiveness of these targets we chose the standard definition of success as at least a $50 \%$ reduction in pain, i.e., the same crite- rion that was previously used in the Medtronic trials for FDA approval [34].

\section{Neuromodulation for DRS}

Where pharmacologic treatments have failed, practitioners have attempted motor cortex stimulation, repetitive transcranial magnetic stimulation, vestibulocochlear stimulation, and DBS to treat chronic pain states $[1,2,5]$. Since its beginnings in 1952, DBS has been used in the treatment of chronic pain syndromes [39]. In 1975 Mazars [40] hypothesized that pain can be caused by a lack of proprioceptive information reaching the thalamus. He believed that this pain could be controlled by stimulation of the spinotha- 
lamic tract to supplement the lost input [40], and through his early work he noted that deafferentation pain could be controlled by thalamic stimulation. One of the earliest studies occurred in 1977; in it, Richardson and Akil [41] tested DBS for the treatment of intractable pain using thalamic targets [42]. However, until a 1989 FDA ruling there was no legislation requiring clinical trials to test the safety and efficacy of DBS. Two of the first FDA-mandated clinical investigations into the efficacy of DBS for the treatment of chronic central pain began in the early 1990s. Although these trials did not meet their primary outcome measures, DBS was approved for use to treat parkinsonian tremor in 1997. Approval provided an opportunity to use DBS for off-label treatment, such as DRS [34].

Current theory broadly postulates that DBS modulates fiber pathways in the pain network in order to treat chronic pain, although the exact mechanism is not understood [2, 21,43-46]. DBS of the nucleus accumbens (NAcc) in control rats prompted a decreased metabolism in the basal ganglia and periaqueductal gray, while metabolism increased in the subiculum [47]. Stimulation of the dorsomedial thalamus increased metabolism in the striatum, the NAcc, the piriform cortex, and thalamus. Dorsomedial stimulation also decreased metabolism in the temporal and cingulate cortex [47]. In the future, these results should be compared to rat or mouse models of DRS to determine if there are similar patterns of metabolism.

Despite some anecdotal success, there has been little controlled research into DBS for use on DRS. Until recently, there were no studies which included experimental blinding or controlled for the confounding factors of the placebo effect [3]. In fact, in a small study it was shown that placebo stimulation actually had a larger effect on pain than actual stimulation, and though none of these patients suffered from DRS it is possible that the same effect persists within the DRS patient population [48]. Additionally, patients may experience a microlesional effect, providing some degree of pain relief in a manner similar to ablative treatments. Hamani et al. [49] found that $50 \%$ of poststroke patients implanted with DBS electrodes experienced effective insertional pain relief lasting up to 7 months. Any conclusions on clinical effectiveness drawn from shorter periods of follow-up must be viewed with increased skepticism, as it becomes unclear if there are any underlying insertional effects at play.

In the 2016 EAN guidelines, evidence for the use of DBS in the treatment of chronic neuropathic pain was found to be of very low quality and effect size. Although the treatment is moderately well tolerated and safe, they were unable to make a conclusive determination on its efficacy [50]. More recently, a double-blind, randomized, sham-controlled crossover trial found that only 1 out of 9 patients suffering from DRS achieved a $50 \%$ reduction in pain following 24 months of stimulation to the ventral capsula/ventral striatal region $[3,51]$. Although this appears to be a disappointing result, their findings will hopefully provide some insight into predictors of the DBS response.

\section{Targets for DBS}

Since its inception, DBS has been used to treat refractory neuropathic pain. By far the oldest treatment targets in DRS patients are the ventral posterior medial/ventral posterior lateral thalamic nuclei (VPM/VPL) and the periaqueductal/periventricular gray matter (PAG/PVG) $[34,38,41,42,52,53]$. We have identified 5 additional targets within the literature for consideration: the ven- tral capsular/ventral stratal region (VC/VS) [3], the centromedian thalamic nucleus (CM) [37], the nucleus ventrocaudalis parvocellularis internis $(\mathrm{Vc})$ [35], the ACC, and the posterior limb of the internal capsule (PLIC) [52, 54].

\section{VPM/VPL Thalamic Nuclei}

The sensory thalamus, made up of the VPM and the VPL, is one of the earliest targets in the treatment of neuropathic pain $[42,52]$. It is currently believed to constitute components of the lateral pain system, and as such the area became a major target of interest in the earliest studies of DBS for DRS [38, 43-45]. Contemporary practice is to specifically target the VPM for facial pain, while the VPL can be a target for arm and leg pain [45]. In 1974 the VPL was added to augment stimulation of the PLIC and provide increased pain relief [55]. During their 1977 study, Richardson and Akil [41] planned to stimulate the anterior PAG of a 63-year-old woman suffering from right brachial plexus pain. However, the procedure did not go as planned and the electrode was implanted into the VPM or, as they called it, the posterior medial thalamus. They noted that stimulation of the VPM provided the most effective pain relief with the fewest side effects. Dieckmann and Witzmann [56] performed implantation into this area in 5 patients; however, they did not achieve any treatment successes within the group. Four years later, Hosobuchi [57] reported that $75 \%$ of patients with permanent implants into the VPM/VPL achieved successful stimulation $(n=8)$. Five patients failed at trial and did not elect implantation. Unfortunately, success in this trial was defined by patientreported satisfaction, making it impossible to determine the actual efficacy of the treatment. Levy et al. [58] conducted a trial in 14 patients with VPL electrodes, 9 of whom were internalized. Long-term success was reported in $60 \%$ of the internalized population (which included 1 PLIC implant) [58]. Similarly, visual analog scale (VAS) scores were not quantified in this study, making it difficult to evaluate the beneficial effect of stimulation.

After reviewing target choices in more recent studies, it would appear that stimulation of the sensory thalamus has fallen out of favor (Table 2). The most recent study reporting satisfactory results occurred in 1995, when Tasker and Vilela Filho [7] achieved success in 3 out of 6 patients with implantations in "parasthesiaproducing" sites which consisted of somatosensory areas. In 2006 a trial was conducted in 11 DRS patients with both PVG and VPL electrodes, and this was the largest cohort since 1987 [59]. Stimulation of the VPL was not only ineffective but actually increased pain in many of the subjects. Only 2 participants elected implantation, with neither of them receiving stimulation to the VPL. The second largest cohort consisted of 6 patients implanted with VPL/PVG electrodes. Individual pain reductions were not disclosed for the group; however, the larger cohort achieved only a 38\% average pain reduction despite exclusion of nonresponders from the analysis [60]. Five DRS patients who underwent DBS implantation were evaluated with VPL stimulation. PVG stimulation alone was superior to either VPL or hybrid stimulation, and thus none of the subjects continued with VPL stimulation [11]. In 5 poststroke patients, electrodes were targeted to the PVG/VPL $(n=4)$ and the VPL $(n=1)$ [61]. One patient with a PVG/VPL implant had successful pain relief; however, a second patient came close (49\% reduction). The remaining 3 patients did not achieve satisfactory pain relief to qualify as treatment success. Young et al. [62] implanted a single patient in the PVG/VPL; however, 50\% pain relief was not achieved. In their retrospective analysis, Kumar et al. [52] 
Table 2. Summary of cases of deep brain stimulation for Dejerine-Roussy syndrome

\begin{tabular}{|c|c|c|c|}
\hline Study & Lead location & Success rate, $\%$ & $\begin{array}{l}\text { Average follow-up, } \\
\text { months }\end{array}$ \\
\hline Lempka et al. [51] $(n=9)$ & $\mathrm{VC} / \mathrm{VS}$ & 11 & 24 \\
\hline Boccard et al. [46] $(n=3)^{\mathrm{a}}$ & $\mathrm{ACC}$ & 100 & 0.25 \\
\hline Rezaei Haddad et al. [35] $(n=1)$ & Vc & 0 & 38 \\
\hline Morishita et al. [72] $(n=1)$ & $\mathrm{VC} / \mathrm{VS}$ and $\mathrm{Vo}$ & 0 & 12 \\
\hline Boccard et al. [77] $(n=1)$ & ACC & 100 & 24 \\
\hline Boccard et al. [76] $(n=3)$ & $\mathrm{ACC}$ & 0 & 9 \\
\hline Son et al. [75] $(n=4)$ & $\mathrm{Vc}$ & 0 & 29.5 \\
\hline Papuc et al. [38] $(n=1)$ & PAG/PVG and VPL & Not specified & Not specified \\
\hline \multirow[t]{3}{*}{ Boccard et al. [60] $(n=23)^{\mathrm{b}}$} & $\operatorname{PVG}(n=10)$ & 0 & 23 \\
\hline & PVG/VPL $(n=6)$ & 0 & 23 \\
\hline & Unclear $(n=7)$ & 0 & 23 \\
\hline Mallory et al. [71] $(n=1)$ & $\mathrm{Nacc} / \mathrm{PVG}$ & 100 & 11 \\
\hline Alves and Asfora [37] $(n=1)$ & $\mathrm{CM}$ & 100 & 6 \\
\hline Franzini et al. [54] $(n=1)$ & PLIC & 0 & 60 \\
\hline Hamani et al. [49] $(n=4)^{\mathrm{c}}$ & $\mathrm{Vc}(n=4)$ & 100 & 6.4 \\
\hline Rasche et al. [59] $(n=2)$ & PVG & 50 & 21 \\
\hline \multirow[t]{4}{*}{ Owen et al. [61] $(n=12)$} & PVG $(n=7)$ & 14 & 24 \\
\hline & PVG/VPL $(n=2)$ & 50 & 24 \\
\hline & PVG/VPL with VPL off $(n=2)$ & 0 & \\
\hline & $\operatorname{VPL}(n=1)$ & 0 & \\
\hline Nandi et al. [11] $(n=5)$ & PVG & 0 & 6 \\
\hline Coffey [34] $(n=28)$ & Not specified & Not specified & 24 \\
\hline \multirow[t]{2}{*}{ Kumar [52] $(n=5)$} & S-th $(n=1)$ & 0 & 6 \\
\hline & $\operatorname{PLIC}(n=4)$ & 25 & 6 \\
\hline Tasker and Vilela Filho [7] $(n=7)$ & $\mathrm{PP}(n=7)$ & 71 & Not specified \\
\hline Young et al. [62] $(n=1)$ & PVG/VPL & 0 & 0 \\
\hline \multirow[t]{2}{*}{ Levy et al. [58] $(n=10)^{\mathrm{a}}$} & $\operatorname{VPL}(n=9)$ & $60^{\mathrm{a}}$ & 82 \\
\hline & $\operatorname{PLIC}(n=1)$ & & \\
\hline Hosobuchi [57] $(n=8)^{\mathrm{a}}$ & VPM/VPL & 75 & 24 \\
\hline Namba et al. [79] $(n=6)^{\mathrm{a}}$ & PLIC & 50 & 24 \\
\hline $\begin{array}{l}\text { Dieckmann and Witzmann [56] } \\
(n=5)\end{array}$ & VPM/VPL & 0 & Not specified \\
\hline \multirow[t]{2}{*}{ Richardson and Akil [41] $(n=1)$} & Rostral to the PAG & 100 & Trial only \\
\hline & Medial to the 3rd ventricle & & \\
\hline Hosobuchi et al. [63] $(n=3)^{\mathrm{a}}$ & PLIC & 100 & Not specified \\
\hline \multirow[t]{2}{*}{ Adams et al. [55] $(n=4)$} & Internal capsule $(n=3)$ & 100 & 12 \\
\hline & $\operatorname{VPL} / \operatorname{PLIC}(n=1)$ & 100 & 12 \\
\hline
\end{tabular}

Total patients implanted with deep brain stimulators for Dejerine-Roussy syndrome. Unless otherwise stated, only patients who underwent pulse generator implantation were included. ACC, anterior cingulate cortex; CM, centromedian nucleus; PAG/PVG, periventricular gray/periaqueductal gray; PLIC, posterior limb of internal capsule; PP, parasthesia-producing sites; S-th, sensory thalamus; Vc, nucleus ventrocaudalis parvocellularis internis; VC/VS, ventral capsular/ventral striatal region; Vo, nucleus ventralis oralis; VPL/VPM, ventral posterior lateral/ventral posterior medial nucleus; VAS, visual analog scale. ${ }^{a}$ Patient was classified as "success" or another descriptive outcome within the paper without VAS quantification. ${ }^{b}$ Pain reduction was given as an average. ${ }^{c}$ The success rate dropped to $0 \%$ by 11 months. 
stated that the single patient who received a stimulation trial to the VPL elected not to undergo implantation.

Most recently, VPL stimulation was combined with PAG/PVG stimulation to augment pain reduction following the development of stimulatory tolerance [38]. While this single case is encouraging, these data are anecdotal and will require randomized controlled trials to substantiate their applicability to larger populations.

VPM/VPL stimulation can prove problematic in poststroke patients, as infarct often destroys the necessary portions of the sensory thalamus [52]. Overall the VPM/VPL has been used with varying efficacy to treat DRS. While some authors have asserted that modulation of the sensory thalamus is the most effective way to treat neuropathic pain, the majority of this evidence comes from older trials $[3,35,40,52,53,56,57,63]$. Following larger controlled trials, stimulation of the VPM/VPL may prove to be a useful adjunct target in the future treatment of DRS; however, there is no contemporary evidence to suggest it can be used to achieve satisfactory pain relief as a solitary target.

\section{Periaqueductal/Periventricular Gray Matter}

Pioneers in DBS initially believed that PAG/PVG stimulation was an ineffective target in the treatment of DRS [64]; however, the PAG/PVG has more recently reemerged as a primary target of interest [59-61]. The PAG/PVG is thought to modulate pain through the opioid pathways which extend from the Raphe nuclei to the dorsal horn of the spinal cord $[21,53,62,65,66]$. In non-DRS neuropathic pain patients DBS has been shown to increase endogenous opioid release in the PAG, although the level of release did not correlate with pain score [67]. In contrast, there has been some anecdotal evidence that PAG stimulation does not increase $\beta$-endorphin levels in DRS patients; this is thought to coincide with the syndrome's clinical resistance to opioids [64]. Studies have shown increased PAG activity in patients experiencing allodynia [18]. While stimulation of the PAG/PVG has had some clinical success in the treatment of neuropathic pain, it is generally recommended only if there is at least a nociceptive component $[11,42,45,52,62]$.

We have identified 24 definitive cases of electrode implantation into the PVG alone $[11,59-61]$ and 16 definitive cases of implantation into the PVG in conjunction with other target sites (Table 2) [38, 60-62]. In cases of pure PVG implantation only 2 patients explicitly achieved greater than $50 \%$ pain reduction. Rasche et al. [59] reported an additional 9 failures to achieve pain relief in a trial. Hybrid implantation had similarly disappointing results, with only 2 patients achieving a greater than $50 \%$ reduction in pain. One patient achieved successful pain reduction with sole stimulation of the accompanying target [49]. Interestingly, combined implantation into the PVG and the NAcc was effective in providing complete pain relief, possibly due to inhibitory projections to the medial thalamus, the amygdala, and the PAG [68-71]. Individual patient data was not provided in the larger cohort described by Boccard et al. [60] and, although they found a statistically significant VAS score decrease of $38 \%$, the data may have been artificially elevated by excluding patients who did not achieve significant pain relief [60]. Accounting for the 7 patients who achieved no pain relief brings the average reduction closer to $26 \%$. Tasker and Vilela Filho [7] found that a trial of PAG/PVG stimulation did not produce pain relief in DRS patients, and in fact it evoked unpleasant effects in nearly all of the patients.

While there may be a theoretical basis for using the PVG as a DBS target, the results do not provide a strong clinical basis for its current use as a solitary target. Further improvements in predicting both response and efficacy are essential for the PVG to become a viable treatment option in routine clinical practice. Larger clinical trials are necessary to determine if PVG/NAcc stimulation warrants further use; currently, evidence is solely anecdotal.

\section{Ventral Capsular/Ventral Striatal Region}

In 2013 Plow et al. [3] proposed a double-blind, randomized crossover study for the treatment of thalamic pain syndrome with stimulation of the anterior limb of the internal capsule/VS. They believed that, since the VS and the anterior limb of the internal capsule are emotional regulators, stimulation could affect the learned sensitized perception of pain, making pain more tolerable [3]. In the trial, 9 patients had electrodes implanted into the VC/ VS; however, only 1 patient achieved $50 \%$ pain reduction following 24 months of stimulation (CTID: NCT01072656) [51]. They did note, however, that patients experienced improvement in the affective component of their pain. An additional patient implanted with VC/VS and ventral oralis electrodes did not achieve satisfactory pain relief [72]. Although stimulation of the $\mathrm{VC} / \mathrm{VS}$ may be a prospective treatment option, there is not enough data to warrant its current use in clinical practice.

Centromedian Thalamic Nuclei

There exists only one instance of CM targeting for the treatment of DRS [37]. The CM is a component of the intralaminar nuclei and it is thought to be involved in processing of the motivational-affective components of pain $[37,73]$. While the one instance of CM use was a treatment success, this is an anecdotal example [37]. At this point the efficacy of the CM is still unclear, as no data exists. As such, stimulation of the $\mathrm{CM}$ is still theoretical in nature and requires controlled investigation into its viability.

Nucleus Ventrocaudalis Parvocellularis Internis

Although DBS to the VPM/VPL has been used to treat DRS for over 40 years, placing multiple electrodes to stimulate both areas of the sensory thalamus simultaneously brings with it an increased chance of surgical morbidity $[35,74]$. In order to reduce this risk, surgeons have begun to target the midpoint between the VPM and the VPL, i.e., the Vc $[35,75]$. Conceptually, stimulation of this midpoint should elicit an effect from both areas with a single electrode implant. Although the Vc may prove to be a viable option for reducing the operative risk of DBS, any opinions on its efficacy rely on incredibly limited data. Four patients failed to achieve $50 \%$ pain relief in the trial [49]. Of the 9 patients who were implanted with Vc electrodes, either alone or in conjunction with other stimulation sites, only 4 achieved greater than $50 \%$ pain relief $[35,49,75]$. However, by 11 months the beneficial effect of stimulation had disappeared in all of the subjects [49]. Additionally, 4 of the cases with failures chose motor cortex stimulation over $\mathrm{Vc}$ stimulation for long-term pain control [75]. The justification for use of the Vc is valid; however, due to the contradictory nature of reported outcomes and the short duration of reported effects, we cannot make a definitive conclusion on the efficacy of this target without data from larger patient cohorts.

\section{Anterior Cingulate Cortex}

Though not initially considered in the treatment of chronic pain, targeting the affective component via the ACC has become a new avenue of interest [46]. We have identified 7 patients with 
DRS who were implanted with electrodes in the ACC $[46,76,77]$. Of this population, 1 patient achieved greater than $50 \%$ pain reduction, 3 did not, and 3 self-reported as "success" without quantifying any pain reduction. Retrospective analysis of DTI in patients with successful ACC stimulations suggests that patients with increased connections from the ACC to the brainstem, and not the precuneus, will benefit more from DBS [46]. Pain reduction is not the only way to evaluate these patients. In fact, it has been reported that quality of life improvements outpace VAS pain score reductions [76]. This is attributable to the apathy that patients may experience; the pain is present but not salient to them. Unfortunately, in targeting the affective component of pain the physician may also modulate affect in other aspects of life [77]. Thus increased apathy may be considered both a benefit and side effect of ACC stimulation. With such limited data it is impossible to draw any definite conclusions about the ACC as a primary target; however, conceptually the target seems to address many shortcomings of prior treatment paradigms. Only future trials will determine if the ACC has a future as a viable treatment target.

Posterior Limb of the Internal Capsule

The internal capsule has been used both as a primary stimulation target and as a secondary site when infarct destroys vital portions of the sensory thalamus [52]. Stimulation of the PLIC is thought to inhibit nociceptive neurons in the sensory thalamus and inhibit neuronal activity in the VPL, leading to increased pain relief $[54,78]$. To date, there are 16 definitively described cases of implantation into the PLIC, with 1 occurring in conjunction with a VPL electrode [52, 54, 55, 58, 63, 79]. Results were considered positive, with 8 out of 15 patients achieving "success". It is unclear if the patient described in the study of Levy et al. [58] achieved long-term relief. Unfortunately, 7 of the successful implants had no VAS quantification, making it impossible to determine what degree of pain relief was considered successful [55, 63]. In this light, there exist only 2 reliable accounts of PLIC stimulation, totaling 5 patients $[52,54]$. Kumar et al. [52] implanted 4 patients with PLIC electrodes as the sensory thalamus lacked the necessary volume for placement. Only 1 patient achieved a minimum of 50\% pain relief. The remaining patient only achieved an initial pain reduction of $40 \%$, which decreased to $25 \%$ over 5 years [54]. Better prognostic techniques and improved stimulation technology may make the PLIC a viable target; however, larger trials are necessary to confirm the currently anecdotal evidence supporting its use.

\section{Discussion}

DRS is characterized by poststroke hemibody central pain which can often be refractory to traditional therapies $[1,2,4,5,37]$. Although Dejerine and Roussy first described the symptoms as a result of thalamic lesions, it is now widely known to also result from extrathalamic lesions which affect the spinothalamic or trigemino-thalamic pathways $[2,4]$. DRS is associated with a reduction in basal thalamic activity on the lesional side, and it may be accompanied by changes in areas mediating affective and emotional components of pain $[18,80]$. Decreased opioid receptor binding within pain circuitry has been reported in DRS patients, likely explaining their poor response to opioids [81]. PET results from 8 DRS patients revealed decreased opioid receptor binding in the lateral prefrontal cortex, the posterior temporal cortex, the insula, the VPM, and the posterior midbrain; blood flow to these regions was unaffected [82]. In fact, it has been hypothesized that endogenous opioid release may contribute to central sensitization leading to DRS [81].

Although there are several proposed theories to explain the occurrence of this persistent central pain, none of them have adequately explained the pathophysiology of the disorder [5]. It is quite likely that the condition is heterogeneous in nature, with differing pathophysiologic mechanisms leading to the same clinical presentation. This mechanism would at least partially explain why patients with similar lesions and clinical conditions have such varied responses to DBS. The failure to accurately locate the cause of DRS is also evidenced by the ineffectiveness of medical therapy. Amitriptyline is currently one of the most effective pharmacologic therapies; however, it only effectively reduced pain in $66 \%$ of the test subjects $[2,5,83]$. Even if the small sample size of the study is representative of the greater population, the $33 \%$ of patients who did not respond to therapy represent a pharmacologically resistant population. It is not uncommon for these patients to take exorbitant amounts of medication with no therapeutic benefit [37].

It is essential that research into DBS for DRS focus on techniques for predicting efficacy. Targets are often chosen from anecdotal evidence, which may explain, in part, the variable outcomes to the procedure. Recently DTI has been used to compare fiber tract connections in patients with successful and unsuccessful DBS treatment [46]. This technique may prove valuable in determining the DBS candidacy of chronic pain patients. Interestingly, a single case of left-sided poststroke pain was abolished after the patient sustained a contralesional infarct to the left postcentral and supramarginal gyrus, suggesting that DRS functions as a bilateral disorder [84]. As right-sided deficits from his left hemispheric infarct resolved, the pain returned to his left side. This presents an interesting possibility for the use of contralateral DBS to target DRS, although primary animal studies are necessary to evaluate clinical safety and efficacy.

Potentially the most significant issue surrounding DBS is the obvious lack of controlled data supporting its use. It is not uncommon practice to enroll patients with mixed pain etiologies, many of which are pathophysiologically distinct from DRS, into larger DBS trials. These 
heterogeneous cohorts produce variable responses which do not extrapolate well to clinical practice $[26,85]$. In the Medtronic DBS trial, one of the largest explorations into the efficacy of DBS, their patient population consisted of at least 15 different causes, many of which responded poorly to DBS $[34,85]$. Treatment trials, when they do occur, are often small and uncontrolled. The recent trial by Lempka et al. [51] represents a positive step towards proving the efficacy of DBS in a randomized controlled environment.

\section{Conclusions}

Although DBS was initially rejected as a treatment option for chronic neuropathic pain, technological improvements in stimulation parameters, lead design, and targeting have made it a viable option for the subset of pain which is refractory to pharmacologic treatment $[1-5,34$,
$35,37,38,42,52,53]$. In situations of refractory pain, DBS can be a valuable last-resort treatment and it has been shown to be capable of providing clinically significant pain reduction. Unfortunately, the poorly understood mechanisms of DRS have limited the potential clinical utilization of DBS. Overall increased insights into the targeting potential of DBS and the physiology of DBS responders have rendered many of the old conclusions about DBS obsolete, opening a gap which needs to be filled with more contemporary case reports and clinical trials. Ideally, further insight into the pathophysiology of DRS and the rapid pace of current technological advancement will enable DBS to become a staple in the treatment of DRS.

\section{Disclosure Statement}

The authors report no conflict of interests regarding the materials, methods, or findings of this paper.

\section{References}

1 Henry JL, Lalloo C, Yashpal K: Central poststroke pain: an abstruse outcome. Pain Res Manag 2008;13:41-49.

2 Kumar B, et al: Central poststroke pain: a review of pathophysiology and treatment. Anesth Analg 2009;108:1645-1657.

3 Plow EB, Malone DA Jr, Machado A: Deep brain stimulation of the ventral striatum/anterior limb of the internal capsule in thalamic pain syndrome: study protocol for a pilot randomized controlled trial. Trials 2013;14:241.

4 Flaster M, et al: Central poststroke pain: current diagnosis and treatment. Top Stroke Rehabil 2013;20:116-123.

5 Oh $\mathrm{H}$, Seo W: A comprehensive review of central post-stroke pain. Pain Manag Nurs 2015;16:804-818.

6 Hong JH, et al: Injury of the spino-thalamocortical pathway is necessary for central poststroke pain. Eur Neurol 2010;64:163-168.

7 Tasker RR, Vilela Filho O: Deep brain stimulation for neuropathic pain. Stereotact Funct Neurosurg 1995;65:122-124.

8 Kumar A, et al: Central poststroke pain can occur with normal sensation. Clin J Pain 2016;32:955-960.

9 Klit H, et al: Early evoked pain or dysesthesia is a predictor of central poststroke pain. Pain 2014;155:2699-2706.

10 DéjerineJ, RoussyG:Lesyndromethalamique. Rev Neurol (Paris) 1906, pp 521-532.

11 Nandi D, et al: Thalamic field potentials in chronic central pain treated by periventricular gray stimulation - a series of eight cases. Pain 2003;101:97-107.
12 Hansen AP, et al: Pain following stroke: a prospective study. Eur J Pain 2012;16:1128-1136.

13 Andersen G, et al: Incidence of central poststroke pain. Pain 1995;61:187-193.

14 Segatore M: Understanding central poststroke pain. J Neurosci Nurs 1996;28:28-35.

15 Sahin-Onat S, et al: The effects of central poststroke pain on quality of life and depression in patients with stroke. J Phys Ther Sci 2016; 28:96-101.

$16 \mathrm{Kim} \mathrm{JH}$, et al: Lesions limited to the human thalamic principal somatosensory nucleus (ventral caudal) are associated with loss of cold sensations and central pain. J Neurosci 2007;27:4995-5004.

17 Morishita T, Inoue T: Brain stimulation therapy for central post-stroke pain from a perspective of interhemispheric neural network remodeling. Front Hum Neurosci 2016;10:166.

18 Moisset X, Bouhassira D: Brain imaging of neuropathic pain. Neuroimage 2007;37(suppl 1):S80-S88.

19 Gopalakrishnan R, et al: Pain anticipatory phenomena in patients with central poststroke pain: a magnetoencephalography study. J Neurophysiol 2016;116:1387-1395.

20 Shih HC, Kuan YH, Shyu BC: Targeting brain-derived neurotrophic factor in the medial thalamus for the treatment of central poststroke pain in a rodent model. Pain 2017; 158:1302-1313.

21 Hosomi K, Seymour B, Saitoh Y: Modulating the pain network - neurostimulation for central poststroke pain. Nat Rev Neurol 2015;11: 290-299.
22 Takatsuru Y, et al: Neuronal circuit remodeling in the contralateral cortical hemisphere during functional recovery from cerebral infarction. J Neurosci 2009;29:10081-10086.

23 Siegfried J, Lazorthes Y, Sedan R: Indications and ethical considerations of deep brain stimulation. Acta Neurochir Suppl (Wien) 1980; 30:269-274.

24 Wilkins RH, Brody IA: The thalamic syndrome. Arch Neurol 1969;20:559-562.

25 Ryder S-A, Stannard CF: Treatment of chronic pain: antidepressant, antiepileptic and antiarrhythmic drugs. Contin Educ Anaesth Crit Care Pain 2005;5:18-21.

26 Agnew DC, Goldberg VD: A brief trial of phenytoin therapy for thalamic pain. Bull Los Angeles Neurol Soc 1976;41:9-12.

27 Vestergaard K, Jansen TS: Treatment of central post stroke pain with selective serotonin reuptake inhibitor. Eur J Neurol 1996;3:169.

28 Attal N, et al: Effects of IV morphine in central pain: a randomized placebo-controlled study. Neurology 2002;58:554-563.

29 Canavero S, Bonicalzi V, Paolotti R: Lack of effect of topiramate for central pain. Neurology 2002;58:831-832.

30 Serpell MG; Neuropathic Pain Study Group: Gabapentin in neuropathic pain syndromes: a randomised, double-blind, placebo-controlled trial. Pain 2002;99:557-566.

31 Takahashi Y, Hashimoto K, Tsuji S: Successful use of zonisamide for central poststroke pain. J Pain 2004;5:192-194.

32 Verma V, Singh N, Singh Jaggi A: Pregabalin in neuropathic pain: evidences and possible mechanisms. Curr Neuropharmacol 2014;12:44-56. 
33 Kalita J, Chandra S, Misra UK: Pregabalin and lamotrigine in central poststroke pain: a pilot study. Neurol India 2017;65:506-511.

34 Coffey RJ: Deep brain stimulation for chronic pain: results of two multicenter trials and a structured review. Pain Med 2001;2:183-192.

35 Rezaei Haddad A, Ughratdar I, Ashkan K: A single thalamic target for deep brain stimulation to treat hemi-body pain syndrome. Acta Neurochir 2015;157:1519-1523.

36 Kelly ML, et al: Barriers to investigator-initiated deep brain stimulation and device research. Neurology 2014;82:1465-1473.

37 Alves RV, Asfora WT: Deep brain stimulation for Dejerine-Roussy syndrome: case report. Minim Invasive Neurosurg 2011;54:183-186.

38 Papuc E, et al: Reduction of thalamic tremor with deep brain stimulation performed for post stroke chronic central pain. Ann Agric Environ Med 2013;1:45-47.

39 Delgado JM, Hamlin H, Chapman WP: Technique of intracranial electrode implacement for recording and stimulation and its possible therapeutic value in psychotic patients. Confin Neurol 1952;12:315-319.

40 Mazars GJ: Intermittent stimulation of nucleus ventralis posterolateralis for intractable pain. Surg Neurol 1975;4:93-95.

41 Richardson DE, Akil H: Pain reduction by electrical brain stimulation in man. 1. Acute administration in periaqueductal and periventricular sites. J Neurosurg 1977;47:178-183.

42 Bittar RG, et al: Deep brain stimulation for pain relief: a meta-analysis. J Clin Neurosci 2005; 12:515-519.

43 Kovanlikaya I, Heier L, Kaplitt M: Treatment of chronic pain: diffusion tensor imaging identification of the ventroposterolateral nucleus confirmed with successful deep brain stimulation. Stereotact Funct Neurosurg 2014;92:365-371.

44 Pereira EA, Aziz TZ: Neuropathic pain and deep brain stimulation. Neurotherapeutics 2014;11:496-507.

45 Boccard SG, Pereira EA, Aziz TZ: Deep brain stimulation for chronic pain. J Clin Neurosci 2015;22:1537-1543.

46 Boccard SG, et al: Tractography study of deep brain stimulation of the anterior cingulate cortex in chronic pain: key to improve the targeting. World Neurosurg 2016;86:361-370. e1-e3.

47 Casquero-Veiga $\mathrm{M}$, et al: Response to deep brain stimulation in three brain targets with implications in mental disorders: a PET study in rats. PLoS One 2016;11:e0168689.

48 Marchand S, et al: Analgesic and placebo effects of thalamic stimulation. Pain 2003;105: 481-488.

49 Hamani C, et al: Deep brain stimulation for chronic neuropathic pain: long-term outcome and the incidence of insertional effect. Pain 2006;125:188-196.

50 Cruccu G, et al: EAN guidelines on central neurostimulation therapy in chronic pain conditions. Eur J Neurol 2016;23:1489-1499.
51 Lempka SF, et al: Randomized clinical trial of deep brain stimulation for poststroke pain. Ann Neurol 2017;81:653-663.

52 Kumar K, Toth C, Nath RK: Deep brain stimulation for intractable pain: a 15-year experience. Neurosurgery 1997;40:736-746, discussion 746-747.

53 Levy R, Deer TR, Henderson J: Intracranial neurostimulation for pain control: a review. Pain Physician 2010;13:157-165.

54 Franzini A, et al: Long-term chronic stimulation of internal capsule in poststroke pain and spasticity: case report, long-term results and review of the literature. Stereotact Funct Neurosurg 2008;86:179-183.

55 Adams JE, Hosobuchi Y, Fields HL: Stimulation of internal capsule for relief of chronic pain. J Neurosurg 1974;41:740-744.

56 Dieckmann G, Witzmann A: Initial and longterm results of deep brain stimulation for chronic intractable pain. Appl Neurophysiol 1982;45:167-172.

57 Hosobuchi Y: Subcortical electrical stimulation for control of intractable pain in humans: report of 122 cases (1970-1984). J Neurosurg 1986;64:543-553.

58 Levy RM, Lamb S, Adams JE: Treatment of chronic pain by deep brain stimulation: long term follow-up and review of the literature. Neurosurgery 1987;21:885-893.

59 Rasche D, et al: Deep brain stimulation for the treatment of various chronic pain syndromes. Neurosurg Focus 2006;21:E8.

60 Boccard SG, et al: Long-term outcomes of deep brain stimulation for neuropathic pain. Neurosurgery 2013;72:221-230, discussion 231.

61 Owen SL, et al: Deep brain stimulation for the alleviation of post-stroke neuropathic pain. Pain 2006;120:202-206.

62 Young RF, et al: Release of beta-endorphin and methionine-enkephalin into cerebrospinal fluid during deep brain stimulation for chronic pain: effects of stimulation locus and site of sampling. J Neurosurg 1993;79:816825.

63 Hosobuchi Y, Adams JE, Rutkin B: Chronic thalamic and internal capsule stimulation for the control of central pain. Surg Neurol 1975; 4:91-92.

64 Hosobuchi Y, et al: Stimulation of human periaqueductal gray for pain relief increases immunoreactive beta-endorphin in ventricular fluid. Science 1979;203:279-281.

65 Yamamoto T, et al: Pharmacological classification of central post-stroke pain: comparison with the results of chronic motor cortex stimulation therapy. Pain 1997;72:5-12.

66 Iranami H, Yamazaki A, Hatano Y: Tramadol challenge for relief of intractable central poststroke pain. Mayo Clin Proc 2006;81:566.

67 Sims-Williams H, et al: Deep brain stimulation of the periaqueductal gray releases endogenous opioids in humans. Neuroimage 2017;146:833-842.
$68 \mathrm{Ma}$ QP, Han JS: Neurochemical studies on the mesolimbic circuitry of antinociception. Brain Res 1991;566:95-102.

69 Ma QP, Shi YS, Han JS: Further studies on interactions between periaqueductal gray, nucleus accumbens and habenula in antinociception. Brain Res 1992;583:292-295.

70 Lorenz J, Minoshima S, Casey KL: Keeping pain out of mind: the role of the dorsolateral prefrontal cortex in pain modulation. Brain 2003;126:1079-1091.

71 Mallory GW, et al: The nucleus accumbens as a potential target for central poststroke pain. Mayo Clin Proc 2012;87:1025-1031.

72 Morishita T, et al: Smile without euphoria induced by deep brain stimulation: a case report. Neurocase 2015;21:674-678.

73 Schmahmann JD: Vascular syndromes of the thalamus. Stroke 2003;34:2264-2278.

74 Zrinzo L, et al: Reducing hemorrhagic complications in functional neurosurgery: a large case series and systematic literature review. J Neurosurg 2012;116:84-94.

75 Son BC, et al: Simultaneous trial of deep brain and motor cortex stimulation in chronic intractable neuropathic pain. Stereotact Funct Neurosurg 2014;92:218-226.

76 Boccard SG, et al: Targeting the affective component of chronic pain: a case series of deep brain stimulation of the anterior cingulate cortex. Neurosurgery 2014;74:628-635, discussion 635-637.

77 Boccard SG, et al: Deep brain stimulation of the anterior cingulate cortex: targeting the affective component of chronic pain. Neuroreport 2014;25:83-88.

78 Richardson DE: Deep brain stimulation for the relief of chronic pain. Neurosurg Clin $\mathrm{N}$ Am 1995;6:135-144.

79 Namba S, et al: Electrical stimulation of the posterior limb of the internal capsule for treatment of thalamic pain. Appl Neurophysiol 1984;47:137-148.

80 Laterre EC, De Volder AG, Goffinet AM: Brain glucose metabolism in thalamic syndrome. J Neurol Neurosurg Psychiatry 1988; 51:427-428.

81 Willoch F, et al: Central poststroke pain and reduced opioid receptor binding within pain processing circuitries: a [11C]diprenorphine PET study. Pain 2004;108:213-220.

82 Maarrawi J, et al: Differential brain opioid receptor availability in central and peripheral neuropathic pain. Pain 2007;127:183-194.

83 Leijon G, Boivie J: Central post-stroke pain - a controlled trial of amitriptyline and carbamazepine. Pain 1989;36:27-36.

84 Helmchen C, et al: Disappearance of central thalamic pain syndrome after contralateral parietal lobe lesion: implications for therapeutic brain stimulation. Pain 2002;98:325-330.

85 Honey CM, Tronnier VM, Honey CR: Deep brain stimulation versus motor cortex stimulation for neuropathic pain: a minireview of the literature and proposal for future research. Comput Struct Biotechnol J 2016;14: 234-237. 